\title{
Percepción de riesgo del Covid 19 en estudiante de enfermería UNESUM
}

\author{
Perception of Covid 19 risk in nursing student UNESUM
}

Percepción de riesgo del Covid 19

\begin{abstract}
Solange Quijije Segovia
Universidad Estatal del Sur de Manabí, solangekarinaquijije@unesum.edu.ec, https://orcid.org/00000002-2880-5180
\end{abstract}

Contacto: solangekarinaquijije@unesum.edu.ec

Recibido: 25-02-2020

Aprobado: 23-06-2020

\begin{abstract}
Resumen
La pandemia del Covid-19, causada por el virus SARS-CoV-2, ha cambiado el modus vivendi de miles de personas en todo el mundo. Tanto este nuevo virus como la enfermedad que provoca eran desconocidos antes de que estallara el brote en Wuhan (China) en diciembre de 2019. Actualmente se ha convertido en una pandemia que ha afectado a muchos países de todo el mundo. El objetivo de esta investigación fue determinar la percepción de riesgo del Covid 19 en estudiantes de enfermería UNESUM para la identificación de la vulnerabilidad de contagio. Se ejecutó un estudio de tipo descriptivo, con método bibliográfico, análisis-síntesis, estadístico y empírico mediante la aplicación de encuestas on-line. Un total de 24 estudiantes de primer semestre fueron encuestados manifestando la percepción de riesgo por la pandemia. Los resultados evidencian que la percepción de riesgo entre los estudiantes es 40\% positiva tomando la información por medios oficiales, realizando autocuidado con medidas de bioseguridad mientras que el $60 \%$ es negativa indicando que aun con medidas preventivas puedan enfermar y contagiar a familiares considerados vulnerables por presentar enfermedades catastróficas, niños, embarazadas y adultos mayores, provocando estrés, depresión y ansiedad, se elaboró un plan de cuidado relacionado con el dominio de la percepción de salud de contraer el coronavirus. Se concluye que a pesar de las medidas adoptadas y escuchadas para contrarrestar la pandemia está continua en aumento conociéndose que dentro de la población en estudio el $16 \%$ fueron portadores de Covid 19.
\end{abstract}

Palabras clave: Covid 19, enfermería, cuidado, percepción de riesgo.

Abstrat

The Covid-19 pandemic, caused by the SARSCoV-2 virus, has changed the modus lived by thousands of people around the world. Both this new virus and the disease it causes were unknown before the outbreak broke out in Wuhan, China, in December 2019. It has now become a pandemic that has affected many countries around the world. The objective of this research was to determine the risk perception of Covid 19 in UNESUM nursing students to identify contagion vulnerability. A descriptive study was carried out, with a bibliographic method, analysis-synthesis, statistical and empirical through the application of on-line surveys. A total of 24 first-semester students were surveyed expressing their perception of risk from the pandemic. The results show that the perception of risk among students is $40 \%$ positive taking the information through official means, performing self-care with biosafety measures while $60 \%$ is negative indicating that even with preventive measures they can become ill and infect family members considered vulnerable by presenting catastrophic illnesses, children, pregnant women and the elderly, causing stress, depression and anxiety, a care plan was developed related to the domain of the health perception of contracting the coronavirus. It is concluded that despite the measures adopted and listened to to counteract the pandemic, it is continuing to increase, knowing that within the population under study $16 \%$ were carriers of Covid 19. 


\section{HIGIA DE LA SALUD}

Keywords: Covid 19, nursing, care, risk perception.

\section{Introducción}

La percepción del riesgo relacionado con la salud es un juicio subjetivo que las personas hacen sobre los peligros que afectan su bienestar personal. Tales juicios dictan acciones de precaución e influyen en la probabilidad de cumplir con las recomendaciones indicadas (García del Castillo, 2012).

Un componente principal de la percepción de riesgo es el concepto de 'susceptibilidad', que se refiere a cómo los individuos califican su probabilidad de contraer una enfermedad específica. La susceptibilidad percibida, también llamada vulnerabilidad percibida, incluye dos dimensiones: la susceptibilidad personal percibida, que es la probabilidad de que uno sea perjudicado por un peligro y la susceptibilidad percibida comparativa, que es la probabilidad percibida de que uno sea más susceptible a un peligro dado en comparación con otras personas de la misma edad y sexo (Urzúa, Vera-Villarroel, Caqueo-Urízar, \& Polanco-Carrasco, 2020).

Expertos de la Organización Panamericana de la Salud (OPS) comenzaron a entrenar a autoridades de salud de las diferentes regiones en los principios de la comunicación de riesgos durante emergencias de salud pública por el Covid 19 (OPS, 2020). La comunicación de riesgos se enfocó en educar en tiempo real los peligros que pueden amenazar a la población. Esa comunicación también considera la percepción que las personas tienen sobre ese riesgo, que en ocasiones puede no coincidir con la de los expertos, en particular cuando se trata de un escenario cambiante y con incertidumbre (Organización Panamericana de la Salud, 2020), (Puig Meneses, 2020).

De esta manera si se facilita información precisa, pronta y frecuentemente en un idioma que las personas entiendan y a través de canales confiables, la población podrá tomar decisiones y adoptar comportamientos positivos para protegerse a sí mismas y a sus seres queridos de enfermedades como COVID-19 (Chih-Cheng, Tzu-Ping, Wen-Chien, Hung-Jen, \& Po-Ren, 2020).

La Organización Mundial de la Salud ejecuta un seguimiento del comportamiento y conocimiento público en 31 países de Europa, así como las percepciones de riesgo que tienen las personas por el coronavirus COVID-19, de manera que las respuestas se conviertan en acciones de política pública. La OMS explica que uno de los elementos más críticos para reducir la transmisión del virus es el comportamiento público, algunas personas tienen la habilidad para detectar el riesgo y reaccionar adecuadamente ante esta situación, mientras
Periodo. Enero - Junio 2020

Vol. 2, Nro. 1, Publicado 2020-06-30

otras personas no tanto, en consecuencia, las manifestaciones de indisciplina social durante la cuarentena (Organización Mundial de la Salud, 2020).

"Para que las medidas de respuesta a la crisis afecten los comportamientos públicos, deben percibirse como coherentes, competentes, justas, objetivas, empáticas o sinceras" (Morelo Jurado, Herrera-Peco, Pérez-Fuentes, \& Gázquez Linares, 2020).

Según lo anterior, la percepción determina nuestras acciones o da lugar a estados internos como actitudes, emociones y motivaciones, hacia un estímulo específico o situación, ¿y cómo se relaciona la percepción y el riesgo? (PuertaCortés, 2020), "el riesgo es la combinación entre la probabilidad o frecuencia de aparición de un determinado suceso y la magnitud de las consecuencias". Desde el enfoque psicológico el riesgo puede ser real o subjetivo, desde lo individual o colectivo (Martínez Calvo, 2017), (Urzúa, Vera-Villarroel, Caqueo-Urízar, \& Polanco-Carrasco, 2020) .

Para la OMS (2002) los factores sociales, psicológicos, políticos, el género y la visión del mundo, influyen en la percepción del riesgo, así como los estereotipos, las motivaciones, las experiencias, las creencias y actitudes (García del Castillo, 2012).

La confluencia de estos factores hacen que las personas estimen o juzguen la realidad de manera diferente, resultado de ello: 1) una percepción de riesgo alta frente al Covid 19, puede ser las personas organizan y regulan su comportamiento para evitar aglomeraciones y reuniones sociales, hacen uso correcto de la mascarilla, conservan el distanciamiento social, ejecutan el lavado de manos y son consecuentes con otras medidas adoptadas en su jurisdicción o 2) infravaloran el riesgo del Covid 19, cuando esto ocurre no se siguen los protocolos de bioseguridad, ni se asumen otras medidas como la cuarentena, no se valoran como importantes los daños potenciales de la enfermedad, pero sí las ventajas inmediatas de asumir ciertos riesgos (Wanyun \& Feng, 2020).

Una percepción de riesgo inadecuada según (Cordobés, 2018), se debe a: presión social (Ej.: "mis familiares dicen que soy exagerado, qué ellos no están contagiados, entonces acudo a la reunión); comodidad (Ej.: "la mascarilla me protege pero me ahoga, me molesta, entonces lo retiro"); la ausencia de perspectiva del riesgo (Ej.: "el COVID 19 no es peligroso o no existe") y adiciono una última condición, la imitación y su valoración (Ej.: “ un vecino no usa mascarilla y sale a la calle, no le ha sucedido nada, entonces hago lo mismo".

Coronavirus $(\mathrm{CoV})$ es la denominación general con el que se identifican a los integrantes de la 
HIGÍA DE LA SALUD

subfamilia Orthocoranavirinae. Con respecto a su taxonomía estos forman parte del orden Nidovirales pertenecientes a la familia Coronaviridae. El nombre de estos virus deriva de la característica forma de su estructura que se asemeja a una especie de corona cuando son observados mediante el microscopio electrónico (Fernández-Rodríguez, Casas, Culebras, Morilla , \& Cohen, 2020).

El SARS-CoV-2 es el nuevo coronavirus causante de la enfermedad por Covid-19 que representa el mayor problema de salud pública global en los actuales momentos, este es un virus provisto de membrana de envoltura con un diámetro que ronda entre los 100 a $160 \mathrm{~mm}$ envuelto por una bicapa lipídica. En su envoltura se encuentra la Glucoproteínas que es la responsable de la formación de las estructuras que sobresalen al exterior de esta membrana y la proteína determinante del tropismo del virus (CENTRO DE COORDINACIÓN DE ALERTAS Y EMERGENCIAS SANITARIAS, 2020).

Los primeros casos de SARS-Cov-2 fueron identificados el 30 de diciembre de 2019 en la ciudad de Wuhan (provincia de Hubei, China) desde aquel entonces el virus se ha transmitido rápidamente en cada uno de los continentes del mundo, exceptuando únicamente la Antártida a tal punto que, la Organización Mundial De La Salud (OMS) el 11 de marzo de 2020 declaró a esta enfermedad como una pandemia de interés internacional (Mehta, y otros, 2020). En la actualidad en el mundo existen aproximadamente 27.303.622 casos confirmados y 892.689 muertes según la Universidad Johns Hopkins localizada en Baltimore, Estados Unidos (El Comercio, 2020).

En América Latina y el Caribe 9.812.945 casos confirmados y 360.358 muertes a causa del Covid 19. En Ecuador, el 29 de febrero de 2020 se confirmó el primer caso de Covid-19 y hasta el día 2 de octubre el país suma 142,056 casos positivos de los cuales 9.948 casos corresponden a la provincia de Manabí incluyendo a los habitantes de la zona sur y 11.702 fallecidos en todo el territorio ecuatoriano (16).

Esta investigación se enmarca dentro de la integración de saberes y conocimientos en la carrera de Enfermería de la Universidad Estatal del Sur de Manabí, donde se pretende conocer la percepción que tienen los estudiantes del primer semestre de la carrera sobre la pandemia del Covid 19. Para ello se realizó búsqueda bibliográfica y se aplicó encuesta vía on-line, finalmente se elaboró un plan de cuidado de enfermería mediante diagnóstico, intervención y resultados.

Las bases teóricas de este proyecto están dadas por las diferentes asignaturas estudiadas en el
Periodo. Enero - Junio 2020

Vol. 2, Nro. 1, Publicado 2020-06-30

semestre. Morfofisiología aporta mediante el estudio morfológico de la acumulación excesiva de parásitos en el intestino. Microbiología y parasitología aporta los contenidos relacionados con los parásitos y sus generalidades (complicaciones, síntomas, diagnóstico, prevención y tratamiento). Farmacología General brinda los contenidos sobre los fármacos $\mathrm{y}$ fitofármacos útiles en el tratamiento de estas y todas las enfermedades, las características de las formas farmacéuticas en las que se puedan presentar, principales componentes químicos, dosis, mecanismo de acción. Metodología de la investigación se incorpora en el proyecto a través de la búsqueda de información adecuada para el desarrollo del mismo y la aplicación de normas bibliográficas. Introducción a la salud pública se liga al proyecto con conocimientos introductorios en cuanto a la salud y sus diferentes conceptos. Finalmente, la asignatura rectora del proceso, enfermería básica II brinda conocimientos en cuanto a los cuidaos de enfermería aplicando el proceso de atención de enfermería (PAE).

El objeto de estudio es la percepción de riesgo que tienen los estudiantes de enfermería de contraer el Covid 19. El objetivo general: Determinar la percepción de riesgo del Covid-19 en estudiantes de enfermería UNESUM. Los objetivos específicos:

- Describir las características microbiológicas del virus, mecanismo de transmisión, manifestaciones clínicas y complicaciones.

- Describir fitofármacos que se comercializan en Ecuador, para tratar enfermedades respiratorias provocadas por coronavirus, atendiendo a su uso, forma farmacéutica, composición química, vía de administración, dosis, RAM, toxicidad e interacciones medicamentosas.

- Analizar como interpretan el riesgo de contagio del Covid 19 los estudiantes de la carrera de enfermería.

- Elaborar un plan de cuidado relacionado con el dominio de la percepción de salud de contraer Covid 19.

Materiales y métodos

Se desarrolla una investigación de tipo descriptiva ya que se analiza de forma general al Covid 19, en el nivel teórico se usó el método bibliográfico para la estructuración de marco teórico y conocer las actualizaciones en la curva de crecimiento de los contagios. Análisis-síntesis para establecer el plan de acción de enfermería y profundizar en la problematización. Estadística para realizar la tabulación de las encuestas. A nivel empírico se realizó encuesta on-line, basadas en preguntas para conocer la percepción de riesgo que tienen los estudiantes. 


\section{HIGÍA DE LA SALUD}

La variable independiente fue el Covid 19 y la variable dependiente la percepción de riesgo que tienen de adquirir la enfermedad.

Resultados

La encuesta on-line fue realizada por 24 estudiantes de primer semestre de la carrera de enfermería UNESUM.

\section{Gráfico $\mathrm{N}^{\circ} 1$}

Comprensión acerca de las características de esta enfermedad.

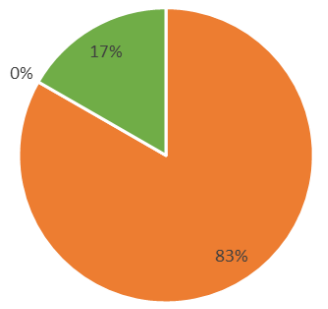

Fuente: Estudiantes de primer semestre de enfermería de la UNESUM

Elaborado por: Investigadores

De acuerdo con los resultados obtenidos, la mayoría de los encuestados, que correspondió al $83 \%$ respondió que conoce las características del virus, mientras que el $17 \%$ muestra incertidumbres sobre el conocimiento de las complicaciones de la enfermedad.

Gráfico $\mathrm{N}^{\circ} 2$

Transmisión del virus

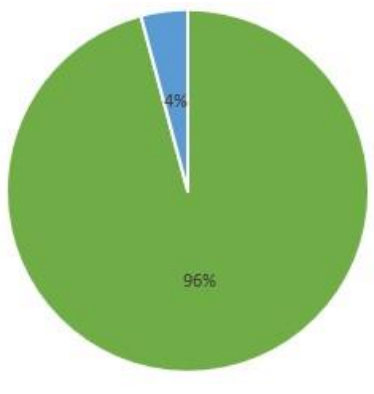

- SI - TAL VEZ = NO

Fuente: Estudiantes de primer semestre de enfermería de la UNESUM

Elaborado por: Investigadores

De acuerdo con los resultados obtenidos, la mayoría de los encuestados equivalentes al $96 \%$ respondieron que conocen como se transmite el virus, mientras que el $4 \%$ mue stra inseguridad al conocer de la transmisión del virus.Gráfico $\mathrm{N}^{\circ} 3$

Conocimiento acerca del medio de contagio del COVID-19.
Vol. 2, Nro. 1,

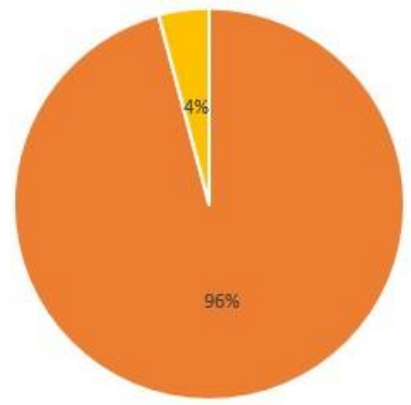

" SI $=$ TAL VEZ $=$ NO

Fuente: Estudiantes de primer semestre de enfermería de la UNESUM

Elaborado por: Investigadores

Según los resultados obtenidos, la mayoría de los encuestados, lo que equivale al $96 \%$, contestaron que conocen el medio de contagio de este virus, mientras que el $4 \%$ muestra dudas del medio de contagio del virus ya mencionado.

Gráfico $\mathrm{N}^{\circ} 4$

Complicaciones respiratorias de esta epidemia.

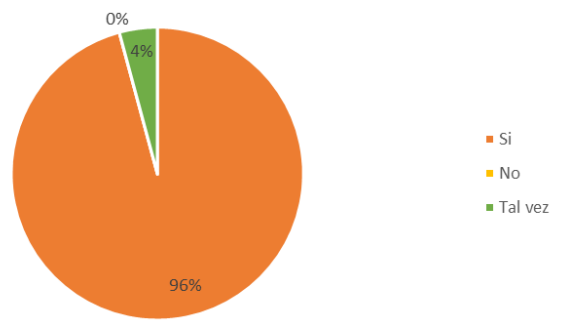

Fuente: Estudiantes de primer Semestre de la carrera de enfermería de la UNESUM

Elaborado por: Investigadores

Mediante los datos observados, se pudo deducir que el $96 \%$ afirman conocer las complicaciones respiratorias q causa el Covi-19, mientras que el $4 \%$ considera que puede provocar problemas respiratorios.

\section{Gráfico $\mathrm{N}^{\circ} 5$}

Medio de comunicación en donde obtienen información actualizada sobre el virus.

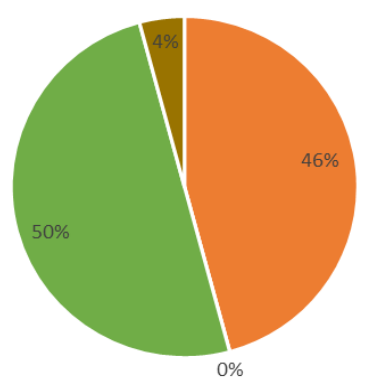

Fuente: Estudiantes de primer Semestre de la carrera de enfermería de la UNESUM

Elaborado por: Investigadores 


\section{HIGÍA DE LA SALUD}

De acuerdo a los resultados, la mayor parte de los encuestados que equivale al $50 \%$ respondieron que usan las redes sociales para tener conocimiento sobre la pandemia, mientras que el $46 \%$ contesto ver la información por canales de $\mathrm{TV}$, el $4 \%$ dio a conocer no utiliza ningún medio de comunicación, se puede dar para evitar el miedo y poder tolerar el encierro.

\section{Gráfico $\mathrm{N}^{\circ} 6$}

Recibimiento de información confiable de organizaciones tales como: OMS, MSP, OPS.

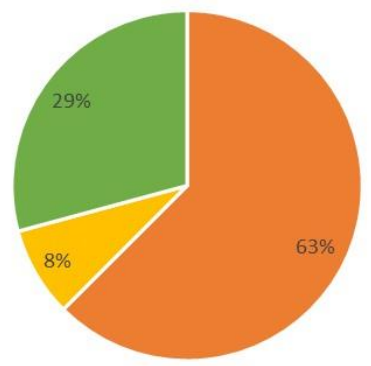

Fuente: Estudiantes de primer Semestre de la carrera de enfermería de la UNESUM

Elaborado por: Investigadores

Mediante los datos obtenidos, se observa que $63 \%$ respondió obtener información de la OMS, MSP, OPS, mientras que el $8 \%$ contesto recibir de vez en cuando la información de dichas entidades y un $29 \%$ dio a conocer no recibir ninguna información.Gráfico $\mathrm{N}^{\circ} 7$

Confían de la información que se difunde en redes sociales con relación al virus.

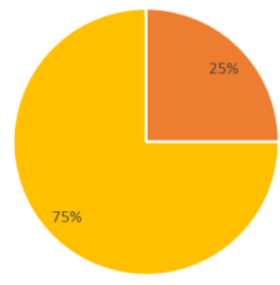

Fuente: Estudiantes de primer Semestre de la carrera de enfermería de la UNESUM

Elaborado por: Investigadores

De acuerdo a los resultados, la mayor parte de los encuestados que equivale al $75 \%$ respondieron que no confían de toda la información que es pública en redes sociales, mientras que el $25 \%$ confía en la información que se publica en las redes sociales.

\section{Gráfico $\mathrm{N}^{\circ} 8$}

Claridad sobre el distanciamiento social para evitar contagio.
ISSN 2773-7705

Periodo. Enero - Junio 2020

Vol. 2, Nro. 1, Publicado 2020-06-30

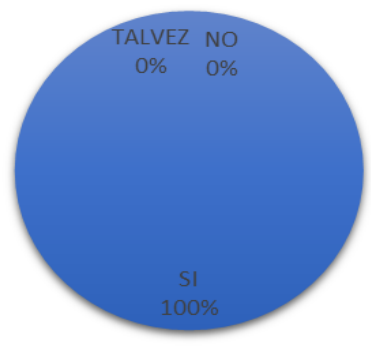

-SI $=$ NO -TALVEZ

Fuente: Estudiantes de primer semestre de enfermería de la UNESUM

Elaborado por: Investigadores

De acuerdo con los resultados obtenidos, la mayoría de los encuestados, que correspondió al $100 \%$ tienen claro el respetar al distanciamiento social para evitar contagios.

Gráfico $\mathrm{N}^{\circ} 9$

Convivencia con el grupo de personas que se encuentra en el rango vulnerable de padecer esta enfermedad.

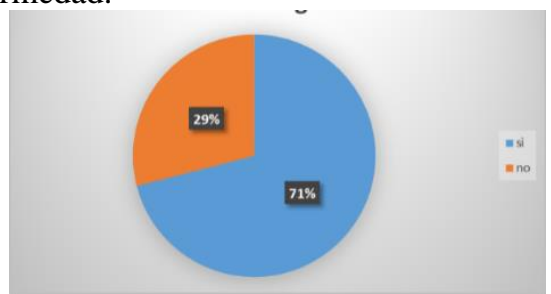

Fuente: Estudiantes de primer semestre de enfermería de la UNESUM

Elaborado por: Investigadores

Según los resultados obtenidos, el $71 \%$ encuestados respondió que convive con personas que padezcan enfermedades crónicas, mientras que el $29 \%$ respondió que no.Gráfico $\mathrm{N}^{\circ} 10$ Se encuentra dentro del grupo de riesgo

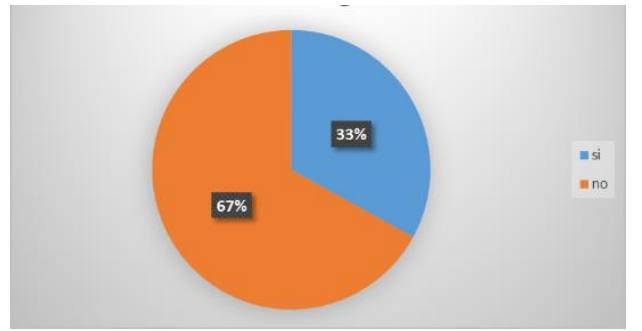

Fuente: Estudiantes de primer semestre de enfermería de la UNESUM

Elaborado por: Investigadores

Datos obtenidos mediante la encuesta revela que la mayoría de los encuestados, correspondiente al $67 \%$ (enfermedades crónicas, hipertensión, enfermedades pulmonares, inmunodeficiencia, cáncer, embarazo, y/o personas mayores de 60 años), respondió que no pertenecen al grupo de riesgo, mientras que el $33 \%$ respondió que sí. Gráfico $\mathrm{N}^{\circ} 11$

Porcentaje de los encuestados que han sido portadores del virus. 


\section{HIGÍA DE LA SALUD}

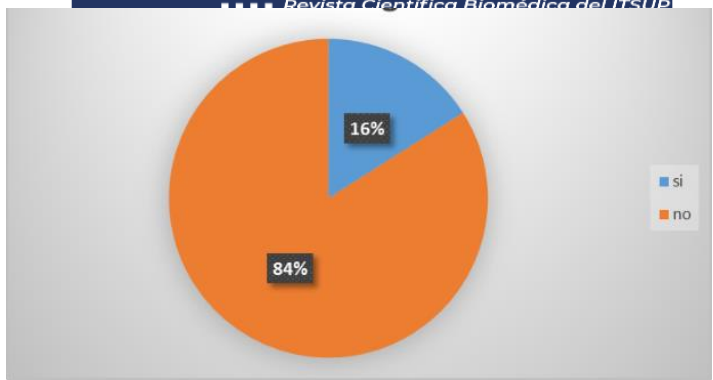

Fuente: Estudiantes de primer semestre de enfermería de la UNESUM

Elaborado por: Investigadores

De acuerdo con los resultados obtenidos, la mayoría de los encuestados, que correspondió al $84 \%$ respondió no han sido portadores de COVID - 19, mientras que el $16 \%$ respondió que si han sido portadores de COVID - 19 .

\section{Gráfico $\mathrm{N}^{\circ} 12$}

Satisfacción en relación a la información que se le brinda a cerca de consejos de bioseguridad

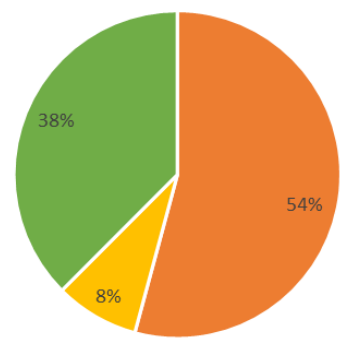

Fuente: Estudiantes de primer Semestre de la carrera de enfermería de la UNESUM

Elaborado por: Investigadores

Datos obtenidos mediante la encuesta revela que la mayoría de los encuestados, correspondiente al $54 \%$ tienen conocimiento de uso adecuado de los equipos de bioseguridad, mientras que un $38 \%$ asegura no estar bien informado de su uso, para finalizar un $8 \%$ dio a conocer que no cuentan con información acerca de las medidas de bioseguridad.

Gráfico $\mathrm{N}^{\circ} 13$

Disponibilidad de equipos de protección

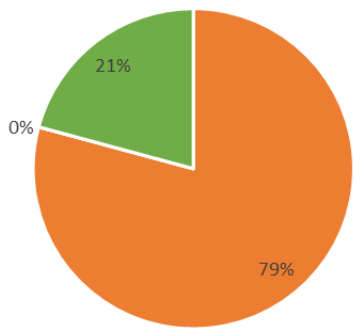

Fuente: Estudiantes de primer Semestre de la carrera de enfermería de la UNESUM Elaborado por: Investigadores

Según los resultados obtenidos, la mayoría de los encuestados, correspondiente $79 \%$, respondió
Periodo. Enero - Junio 2020

Vol. 2, Nro. 1, Publicado 2020-06-30

que cuenta con todos los equipos de protección, mientras que el $21 \%$ respondió que contaba con los más básicos.

\section{Gráfico $\mathrm{N}^{\circ} 14$}

Problemas académicos por acción de la pandemia.

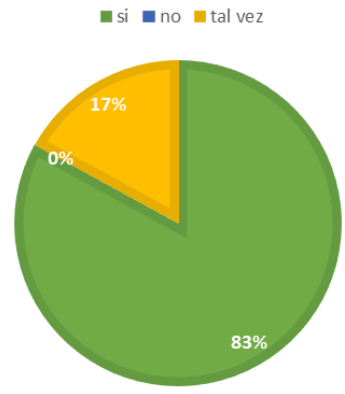

Fuente: Estudiantes de primer Semestre de la carrera de enfermería de la UNESUM Elaborado por: Investigadores

Según los resultados obtenidos, la mayoría de los encuestados, correspondiente al $83 \%$, respondió que la pandemia es un factor influyente en los estudios, mientras que el $17 \%$ respondió que no.

\section{Gráfico $\mathrm{N}^{\circ} 15$}

Efectos psicológicos provocados por el aislamiento.

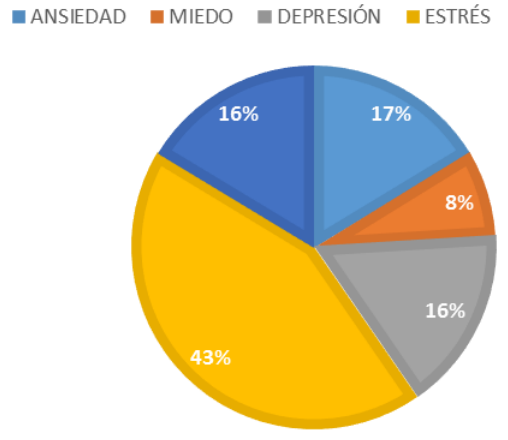

Fuente: Estudiantes de primer Semestre de la carrera de enfermería de la UNESUM

De acuerdo con los resultados obtenidos, la mayoría de los encuestados, que correspondió al $41 \%$ respondió que el aislamiento le ha provocado estrés, existió una igualdad de un $17 \%$ donde representa, ansiedad, depresión y ninguna, de las respuestas obtenidas, por último, un $8 \%$ respondió que representa miedo. Plan de cuidado Para los estudiantes de la carrera de enfermería UNESUM

\section{Diagnóstico NANDA}

DOMINIO 09 - CLASE 0100069 Cambio en los patrones de comunicación habituales. Alto grado de amenaza. Crisis situacionales $0 \quad$ de maduración.

Factores relacionados: Alteración de las percepciones

\section{Resultados NOC}


ISSN 2773-7705

HIGIA DE LA SALUD

1704 Creencias sobre la salud: amenaza percibida

1302 Superación de problemas

1504 Soporte socialIntervenciones NIC

5820 Disminución de la ansiedad

Utilizar un enfoque sereno que dé seguridad

Proporcionar objetos que simbolicen seguridad

Crear un ambiente que facilite la confianza

Animar la manifestación de sentimientos, percepciones y miedos

$5440 \quad$ Aumentar los sistemas de apoyo

Determinar la conveniencia de las redes sociales existentes.

Determinar el grado de apoyo familiar.

Determinar el grado de apoyo económico de la familia.

Remitir a programas comunitarios de fomento / prevención / tratamiento / rehabilitación, si procede.

Diagnóstico NANDA

DOMINIO 06 - CLASE 0100120 Pérdida de algún familiar. Enfermedad actual $\mathrm{m} / \mathrm{c}$ Conducta inconsistente con los valores

Factores relacionados: Baja autoestima situacional

\section{Resultados NOC}

1205 Autoestima

1305 Adaptación psicosocial: cambio de vida Intervenciones NIC

Apoyo emocional: Escuchar las expresiones de sentimientos y creencias.

Apoyar el uso de mecanismos de defensa adecuados

Proporcionar apoyo durante la negación, ira, negociación y aceptación de las fases del sentimiento de pena.

5400 Potenciación de la autoestima

Facilitar un ambiente y actividades que aumente la autoestima.

Reconocer la importancia de cultura, religión, raza, género y edad en la autoestima y niveles de autoestima en el tiempo.

Reconocer la importancia del interés y apoyo de los padres en el desarrollo de un auto-concepto positivo en sus hijos.

\section{Diagnóstico NANDA}

DOMINIO 01 - CLASE 0200078 Impotencia. Complejidad del sistema de cuidados de la salud. Dificultades económicas. Déficit de conocimientos.

\section{Resultados NOC}

1803 Conocimiento: proceso de la enfermedad

Intervenciones NIC

5520 Facilitar el aprendizaje

Establecer la información en una secuencia lógica.

Proporcionar materiales educativos para ilustrar la información importante y/o compleja.
Periodo. Enero - Junio 2020

Vol. 2, Nro. 1, Publicado 2020-06-30

Fitofármacos comercializados en Ecuador para el tratamiento de infecciones respiratorias basadas en evidencia

Orégano, jengibre, hojas de eucalipto, cedrón, menta, uña de gato, ajo.

Los fitofármacos constituyen una terapia que cuando se realiza sobre base científicas y técnicas, se convierte en una alternativa necesaria en nuestro país, por muchas razones. Estos medicamentos deben tener calidad total para que la población tenga acceso a un tratamiento medicamentoso seguro, eficaz, económico, de acuerdo a informes emitidos por medios de comunicación, redes sociales que son utilizados como infusión, vaporizaciones y ungüentos tópicos.

Ficha del fitofármaco

Fitotux (antitusígeno).

Ingredientes activos, Composición cuantitativa y Grupos químicos o principios activos responsables de la actividad terapéutica del producto.

Cada $100 \mathrm{~mL}$ contienen $1 \mathrm{~g}$ de extracto seco estandarizado de hojas de hiedra (hedera hélix L. con un contenido de hederasaponina $\mathrm{C}$ de $11 \%$ a $15 \%)$.

Artículos científicos que avalen la actividad farmacológica y toxicológica del producto o sus principios activos.

Según la European Scientific Cooperative on Phytotherapy (ESCOP), los extractos de hojas de hiedra desecadas, cuyo efecto terapéutico en enfermedades de las vías aéreas se debe a las propiedades secretolíticas (17) espasmolíticas y antitusivas de las saponinas del grupo glucósidos que este producto contiene (18). El preparado natural es bien tolerado y alivia la tos; por lo tanto, sería útil en el tratamiento de pacientes con resfrío común, bronquitis o enfermedades del tracto respiratorio que se asocian con la producción de moco. (19)

Clasificación farmacológica

Antitusígeno: Indicación terapéutica

Es un expectorante para el tratamiento temporal de los síntomas asociados a las afecciones de las vías respiratorias superiores, facilitando la expulsión de las flemas.

Forma farmacéutica

Jarabe

Vía de administración: Oral

Dosificación: Adultos: 1 cucharadita de 3 a 4 veces al día. Niños de 10 a 15 años: 1 cucharadita de 2 a 3 veces al día. Niños de 5 a 10 años: 1/2 cucharadita de 3 a 4 veces al día. Niños de 2 a 5 años: $1 / 2$ cucharadita 2 veces al día.

Efectos adversos conocidos: Se desencadena un aumento en la producción de surfactante en el epitelio pulmonar, que por una parte favorece la reducción de la viscosidad del moco (efecto secreto lítico) y por otra disminuye la 


\section{HIGÍA DE LA SALUD}

concentración intracelular del calcio en la célula del músculo bronquial causando broncodilatación (efecto espasmolítico).

Toxicidad: No se ha documentado hasta la fecha Contraindicaciones y advertencias

Hipersensibilidad a alguno de sus componentes. Embarazo y lactancia

Interacciones medicamentosas

No se conocen interacciones en caso de administración simultánea de FITOTUX y otros medicamentos.

Precauciones en el uso: No se han descrito hasta el momento

Modalidad de venta

Venta libre

Modalidad de producción

Nuestros productos provienen de Laboratorios certificados y registrados ante INVIMA en Colombia. (Jarabe)

\section{Conclusiones}

El Covid-19 es la enfermedad causada por una familia de virus denominados coronavirus, los cuales causan infecciones respiratorias y se transmiten a través de las gotículas despedidas por una persona infectada, entre los síntomas más comunes son fiebre, tos seca y cansancio, los síntomas menos habituales pueden ser: dolores y molestias, congestión nasal, conjuntivitis, diarrea, pérdida de gusto u olfato. Los síntomas aumentan gradualmente y pueden causar complicaciones como: Neumonía y problemas respiratorios, insuficiencia de varios órganos,
Periodo. Enero - Junio 2020

Vol. 2, Nro. 1, Publicado 2020-06-30 problemas cardíacos, infección pulmonar, coágulos sanguíneos, lesión renal aguda.

Las plantas medicinales que se usan para realizar fitofármacos en Ecuador pueden variar entre orégano, hojas de eucalipto, y uno de los fitofármacos más comunes es el Fitotux. Es un expectorante que trata los síntomas asociados a las afecciones de las vías respiratorias superiores. Se ha elaborado un plan de cuidados basado en los diagnósticos NANDA - NIC - NOC, con sus respectivas clases y dominios.

El $90 \%$ de los estudiantes de la carrera enfermería de la UNESUM conocen las características del virus, un total de los encuestados saben cuál es la manera de contagio, su transmisión, a pesar de tener conocimiento la percepción de riesgo es alta sobre todo por el estrés que ocasiona el escuchar cada día el aumento de casos de Covid 19 en Ecuador. Para otros la manera de sobrellevar la pandemia por ha sido para muchos quedarse en casa, respetar la cuarentena y hacer actividades distractoras como leer, ver vídeos, escuchar música, o cuidar a sus familiares. En el caso de los síntomas la población encuestada reporta que se le presentan con mayor intensidad "La ansiedad" y "La falta de sueño": el primero refiere claramente el componente psicológico del estrés y el segundo normalmente se encuentra asociado a problemas de índole psicológico como lo sería la misma ansiedad.

\section{Colaboradores de Investigación:}

Andrade Pico Nicole, Bravo Alcívar Wendy, Castillo Ramos Erick, Cedeño Rivas Valentina, Cevallos Flores Doménica, Chacha Sisalema Holger, Chávez Roldán Saskia, Chica Santana Anthony, Demera Zambrano Andrea.

\section{Bibliografía}

CENTRO DE COORDINACIÓN DE ALERTAS Y EMERGENCIAS SANITARIAS. (2020). Recuperado el 04 de 10 de 2020, de www.mscbs.gob.es. [online]: Available from: https://www.mscbs.gob.es/profesionales/saludPublica/ccayes/alertasActual/nCov/documen tos/20200317_ITCoronavirus.pdf.

Chih-Cheng, L., Tzu-Ping, S., Wen-Chien, K., Hung-Jen, T., \& Po-Ren, H. (2020). Severe acute respiratory syndrome coronavirus 2 (SARS-CoV-2) and coronavirus disease-2019 (covid-19): The epidemic and the challenges. International Journalof Antimicrobial Agents, 55(3).

Cordobés, R. (2018). Recuperado el 04 de 10 de 2020, de prevenblog.com: Disponible en https://preven.com-gestionar-la-percepción-del-riesgp

El Comercio. (2020). Ecuador documenta 717 nuevos casos de covid-19 en las últimas 24 horas; muertes en el contexto de la pandemia suman 11 702. COE Nacional, Redacción el comercio.com, Quito.

Fernández-Rodríguez, A., Casas, I., Culebras, E., Morilla , E., \& Cohen, M. (2020). COVID-19 and postmortem microbiological studies. Revista Espanola de Medicina Legal, 46(3), 1-6. 
ISSN 2773-7705

HIGÍA DE LA SALUD

Periodo. Enero - Junio 2020

Vol. 2, Nro. 1, Publicado 2020-06-30

García del Castillo, J. (2012). Concepto de percepción de riesgo y su repercusión en las adicciones. Salud

y drogas [Internet], 12(2), 133-151. Obtenido de Recuperado de:

https://www.redalyc.org/articulo.oa?id=83924965001

Martínez Calvo, S. (2017). Uso y abuso del término percepción de riesgo. Revista Cubana de Salud Pública, 43(3), 1-7.

Mehta, P., McAuley, D., Brown, M., Sánchez, E., Tattersall, R., \& Manson, J. (2020). COVID-19: consider cytokine storm syndromes and immunosuppression. Lancet (London, England), 395(10229), 1033-1034.

Morelo Jurado, M., Herrera-Peco, I., Pérez-Fuentes, M., \& Gázquez Linares, J. (Agosto-Septiembre de 2020). Análisis de la amenaza percibida por la COVID-19 en población española. Atención Primaria, 52(7), 515-516.

OPS. (2020). Consideraciones psicosociales y de salud mental durante el brote de Covid 19. Recuperado el 03 de 10 de 2020, de Disponible en https://www.paho.org/es/documentos/consideraciones-psicosocialessalud-mental-durante-brote-covid-

19?gclid=EAIaIQobChMIzpuxoaT36gIVEYvICh3tzwvXEAAYASAAEgk1c_D_BwE

Organización Mundial de la Salud. (2020). Recuperado el 02 de 10 de 2020, de www.who.int [online]: Available from: www.who.int

Organización Panamericana de la Salud. (2020). La OMS caracteriza al Covid 19 como una Pandemia. Web, OPS.

Puerta-Cortés, D. (2020). Percepción de riesgo frente al Covid 19 y los nuevos retos. Psicología desde el Caribe, 37(3), 1-5.

Puig Meneses, Y. (2020). Recuperado el 01 de Octubre de 2020, de Granma.cu: http://www.granma.cu/cuba-covid-19/2020-07-24/percepcion-de-riesgo-ante-la-covid-19-reto-del-dia-adia-24-07-2020-23-07-20

Urzúa, A., Vera-Villarroel, P., Caqueo-Urízar, A., \& Polanco-Carrasco, R. (2020). La Psicología en la prevención y manejo del COVID 19. Aportes desde la evidencia inicial. Ter Psicol [online], 38(1). doi:http://dx.doi.org/10.4067/S0718-48082020000100103

Wanyun, S., \& Feng, H. (Septiembre de 2020). Confidence in political leaders can slant risk perceptions of COVID-19 in a highly polarized environment. Social Science \& Medicine, 261(1-7). doi:https://doi.org/10.1016/j.socscimed.2020.113235 